\title{
EL GÉNERO DE LOS COMPUESTOS
}

El género de los compuestos presenta en castellano algunos problemas de interés especial. A los factores de forma y significación, que intervienen en general en todas las vacilaciones y cambios de género, se agrega un factor nuevo: la conciencia etimológica (de los elementos componentes o del proceso formativo), o bien la pérdida de esa conciencia. Así, la voz compuesta puede diferir en género de la simple (o de las simples) de que procede. Vamos a estudiarlo en toda su amplitud, para lo cual pasamos a analizar los diversos tipos de composición.

\section{Compuestos de sustantivo y prefijo}

En general, el compuesto conserva el género del simple: el disfavor, el sinsabor, el confin, el perfil (<lat. p e r - f i l u m), el pronombre, el traspié, la sinrazón, la contraorden, la desazón, la inacción, el contraveneno, el solomo, el pretexto, la contramarca, la sobremano, la postdata, la anteiglesia, la trastienda, la socapa, etc. Pero a veces varía. Aun la lengua erudita suele incurrir en inconsecuencia: el fonema de los lingüistas frente a la epifonema de los retóricos (los primeros respetan el neutro latino y griego, los segundos se àtienen a la analogía $)^{1}$. En la lengua general sólo hemos encontrado

1 Epifonema figura como f. en el Dicc. Aut. (documenta muchas Epiphonemas, en la Eloqüencia española de Jiménez Patón) y luego en todas las ediciones del Dicc. Acad. Lo encontramos como f. en todos los tratadistas de retórica y preceptiva: Hermosilla, Coll y Vehí, Luis Alberto Sánchez, Gayol Fernández, etc. El Dicc. enciclopédico hispanoamericano usa sistemáticamente el $\mathrm{f}$., y lo documenta además en Jovellanos. La Enciclopedia Espasa dice: "La palabra epifonema es f. según los diccionarios y los tratados de preceptiva literaria. Pero respecto de ella nos permitiremos hacer algunas observaciones encaminadas a demostrar que epifonema pertenece al género m." Trata de demostrar que "debe" pertenecer al m., porque es el género que corresponde al neutro latino y porque la Academia ha aceptado el telefonema; el f. lo considera "un error perpetuado de unos escritores a otros, por no haber fijado nadie la atención sobre el particular" (un "error" sería también el f. de (a)postema, pócima, broma, cataplasma, categorema, cima, coma, signo de puntuación, crema 'diéresis', cuaresma, chusma, diadema, estratagema, flema, pantomima, salma, zeuma, etc.). De todos modos, es posible que haya una tendencia actual a hacerlo $\mathrm{m}$. como fonema y telefonema. El Diccionario de la literatura española (Madrid, 
tres casos anómalos: antifaz, contrapeste y trasluz². Vamos a analizarlos:

$f a z(<\mathrm{fac}$ i es) es f. sin vacilación, pero antifaz es siempre $\mathrm{m}$. (véase el Dicc. hist., que lo documenta desde el Amadis, Cervantes y Alarcón); puede haber contribuído al cambio la acción convergente de la $a$ - y la terminación $-a z^{3}$, y quizá también la influencia de disfraz; la lengua general mantiene el género etimológico en la sobrefaz, la sobrehaz y la contrahaz, pero en la Argentina se dice el sobrehaz de las telas (terciopelo, brocado, etc.), quizá por influencia de el haz 'gavilla' ( $h a z$ 'faz' es cultismo desconocido en el habla popular);

peste es f. sin vacilación, pero contrapeste 'remedio oportuno contra la peste' figura como m. desde el Dicc. Aut. hasta el actual Dicc. Acad.; Bello, Gramática, § 186, lo mencionaba entre los sustantivos que conservan el género del simple; Baldomero Rivodó, Tratado de los compuestos, 2 a ed., París, 1883 , pág. 29, lo daba como m. y f.; el m. quizá presuponga remedio: un (remedio) contra (la) peste; de todos modos, ya no es palabra corriente;

luz es f. sin vacilación, pero es general el trasluz, al trasluz; Bello, Gram., $\$ 176$, le daba el género del simple, pero Cuervo, Nota 37 , observaba que había sido siempre m.; quizá haya influído tragaluz, regularmente m.; en la Argentina, según Selva, Guia del buen decir, págs. 21-22, se dice vulgarmente la trasluz y la tragaluz, sin duda por influencia de la luz, pero también encontramos el contraluz, usado

1949), después de decir: "Quintiliano la define...", usa el epifonema. Así, en m., lo usan algunos profesores en la Argentina, Venezuela, México, etc. - De modo semejante, diasyntaxis figura como m. en el Dicc. Aut., con testimonio del Bachiller DE la Torre, Visión deleitable ("del diasyntaxis"), frente a la sintaxis, pero en este caso el $\mathrm{m}$. no tiene en su apoyo la etimología.

* Aparentemente hay algunos otros, pero son de carácter distinto:

el policlinico no es un derivado de la clinica (sí lo es la policlínica), sino sustantivación de el hospital policlinico:

la sobrepelliz se debe quizá a la pelliza; el sobrepelliz persiste en Lerín (Navarra), según informe de Amado Alonso, y en México, la Argentina y Perú; no existe que sepamos * pelliz;

el trascol 'falda de cola que usaban las mujeres', hoy anticuado;

el contraseño alterna en la lengua antigua con la contraseña; todavía lo usa Ciarlos Coloma en su traducción de Tácito (col. Austral, Buenos Aires, 1944, pág. 149):

el enfaldo no es compuesto de falda, sino postverbal de enfaldar;

el transflor o el trasflor, como término de pintura, no es un compuesto de flor, sino postverbal de tra(n)sforar.

También hay que considerar aparte el desgano, que no es derivado de la gana, sino postverbal de desganar (se usa en la Argentina, México, Venezuela y gran parte de América y España; el Dicc. Acad. lo admite como equivalente de desgana). Y el trasnocho o el trasnoche, postverbales de trasnochar. Etc.

"Véanse mis trabajos "Vacilaciones y cambios de género motivados por el artículo", en $B I C C, \mathrm{~V}, 1949$, págs. 21-32, y "Género de los sustantivos en -e y en consonante", en EMP, III, págs. 159-202 (págs. 194-195: los sustantivos en -az son regularmente masculinos). 
por Polettı, La pintura en Francia, Buenos Aires, 1946, pág. $4^{6}$ (le consultamos sobre este uso, y nos dice que así lo ha visto siempre), cuando en este caso la lengua culta ha conservado el f. etimológico.

El Dicc. Acad. registra otras dos anomalías, del lenguaje técnico:

el sobrecruz 'cada uno de los cuatro brazos o rayos que la rueda de la azuda lleva en los lados de las cruces', y la sobreplán 'cada una de las ligazones que, de trecho en trecho, se colocan sobre el forro interior del buque'; pueden deberse a influencia de el rayo o la ligazón respectivamente, o de otras palabras con que se asocien.

Diverso carácter tienen las vacilaciones de vislumbre y relumbre, ya que lumbre ha vacilado bastante hasta fijarse modernamente en el f.; la lengua general se ha decidido por la vislumbre y el relumbre, con vacilaciones ${ }^{4}$. En realidad, no son compuestos de lumbre, sino postverbales de vislumbrar y relumbrar. Del mismo modo se han usado el deslumbre, postverbal de deslumbrar, y por lo tanto m., y el relumbro, postverbal de relumbrar.

Es interesante señalar que los tres casos de inconsecuencia de la lengua general, el antifaz, el contrapeste, el trasluz (en la Argentina además el contraluz), se han producido a favor del m., que es, como veremos, el género predominante en los compuestos.

\section{Compuestos de sustantivo Y adjetivo}

a) Con adjetivo antepuesto.--Se conserva regularmente el género del sustantivo: la primavera, la vanagloria, la malacuenda, la malagana, la buenaventura, la falsarregla, unas mialmas, la altiplanicie, el medioevo, el plenilunio, el bajorrelieve, etc. Pero hay algunos casos regionales de interés especial:

En la lengua general es m. mediodia, como dia, pero en algunas regiones la terminación tiende a llevarlo al f.: esta mediodia en el habla vulgar de España"; la mediodia en el judeoespañol de Salónica y Bitoli (Monastir), que Crews ${ }^{6}$ explica por influencia de la noche, la tadre 'la tarde', la mañana, o bien por la pasadia, que se usa en judeoespañol.

En la lengua general son femeninos altamar, pleamar, bajamar,

1 Véase $E M P$, III, pág. 177 y nota.

- Tomás Navarro, RFE, XII, 1925, pág. 364, nota 2.

${ }^{-}$C. M. Crews, Recherches sur le judéo-espagnol dans les pays balcaniques, Paris, 1935, nota 362. En Constantinopla también las dias, junto a el dia, los dias (M. L. WAGNER, Beitrăge zur Kenntnis des Judenspanischen von Konstantinopel, Wien, 1914, §124). También Max A. LuRIA, A study of the Monastir dialect of Judeo-Spanish, based on oral material collected in Monastir, Yugoslavia,. New York, 1930, pág. 138, registra meyedie f., como meyenochi. 
formados en una época en que mar era predominantemente f. ${ }^{7}$; modernamente, al fijarse el $\mathrm{m}$. de mar, comienza a manifestarse la tendencia a llevar esos compuestos al m.: el pleamar usó García Lorca, quizá de su habla andaluza; en la Argentina hay personas que dicen el pleamar, el bajamar ${ }^{8}$. En cambio es regular el verdemar, como el verdemontaña, el verdevejiga, masculinos como todos los nombres de colores.

La milhojas es nombre de una planta $(\doteq$ la milenrama del Dicc. Acad.); pero como nombre de un pastel hemos oído en España y la Argentina un milhojas. Análogamente, en Cuba, el milflores, nombre de un bejuco, quizá el mismo que en Chile llama el pueblo el multiflor o el motiflor y en Cauca (Colombia) el milflor 9 . Del mismo modo, la cincoenrama, una hierba, frente a el sietenrama, una planta (Dicc. Acad.). Los nombres de árboles y arbustos tienden a ser regularmente masculinos: el todaespecie, árbol de Venezuela.

En España se dice el altavoz, los altavoces (en contraste con la voz), sin duda porque presupone el (aparato de) altavoz; en México el magnavoz (en la Argentina y Venezuela, y también en México, los altoparlantes, traducción del francés hautparleur).

La tendencia analógica es débil. Salvo en algunos casos dialectales ${ }^{10}$, el género del simple gobierna el género del compuesto.

b) Con adjetivo pospuesto.-Por lo común, el compuesto conserva el género del simple: el hilván, el aguaverde (f. según la Academia), el paloduz, la cañaduz (en Andalucía, Colombia, etc.), el carnposanto, el montepio, el murciego, el petirrojo, el rabihorcado, la avutarda (<avis t a r d a), la melcocha, la nochebuena, la cañavera, etc. Cuando el compuesto termina en - $o$ o en - $a$ el género se mantiene $\sin$ vacilación, pero si termina en $-e$ o en consonante y los elementos se funden hasta el punto de perderse el sentimiento etimológico, el compuesto puede cambiar de género, como los demás sustantivos de esas terminaciones. Tenemos en primer lugar, por su número e importancia, los compuestos de agua. No ha habido nunca vacilación en el género de agua, a pesar del artículo el, porque la terminación - $a$ mantiene la palabra en el f.; pero al cambiar de terminación por amalgama con un adjetivo, el artículo tiende a llevar el compuesto al $\mathrm{m}$. Hemos reunido los siguientes casos:

"Véase mi artículo "Vacilaciones de género en los monosílabos", en $B A V$, XVIII, 1950, págs. 194-195.

${ }^{8}$ A. Alonso y P. Henríquez Ureña, Gramática castellana, vol. II, Buenos Aires, 1939, $\S 66$.

- Santamaría; Malaret, Suplemento; Román, Dicc. de chilenismos, s. v. multiflor (nombre de una planta y de una flor, la rosa multiflora); Suárez, Dicc. de voces cubanas, registra milfores como $\mathrm{f} .=$ milrosas $\mathbf{f}$.

${ }^{10}$ Sin duda se podrían multiplicar los ejemplos. Uno curioso encontramos en Chile: los pichigrasas 'particulas menudas de grasa que se extraen de la res al beneficiarla' (Román, s. v.), del araucano pichi 'pequeño' y el esp. grasa. 
aguardiente es siempre m. (Dicc. hist.; Dicc. Acad.); en gallego augardente, siempre f. (GARcía DE Diego, Gram. gallega, pág. 91); aguachirle es f. para la Academia (Dicc. hist.; Dicc. Acad.), y ése era el uso clásico ("patos del aguachirle castellana..."), pero se usa también en m. según García DE Diego, Gram. histórica, § 131);

aguarrás, que era f. para Palomino de Castro, en 1715 (GILI GAYis, Tesoro lexicográfico, s. v.), y para Bello, Gram., § 180 , es m. para la Academia (Dicc. hist.; Dicc. Acad.), que se atiene al uso actual; aguafuerte 'lámina o grabado al agua fuerte', que la Academia registra como f. (Dicc. hist.; Dicc. Acad.), y que es f. en francés (une eau-forte), lo hemos oído siempre como m.: los aguafuertes, un aguafuerte magnifico (los aguafuertes en La quimera de EMILIA PARDo BAZÁN; pero agua fuerte acabada y vigorosa en el académico G. DE Amezúa, Epistolario de Lope de Vega, vol. II, pág. 349; Jorge LuIs BORGES, que usa aguafuertes alabadas en Sobre el "Vathek", dice la masculina aguafuerte, jugando con el género, en Seis problemas para don Isidro Parodi, que publicó con el seudónimo de H. Bustos Domecq, Buenos Aires, 1942, pág. 149);

aguazul, aguazur o algazul son $\mathrm{m}$. (en rigor no son compuestos de agua ni de alga + azul, pero probablemente se han sentido así por etimología popular);

aguadulce 'bebida que se prepara con panela' en Colombia, es m. (MalareT).

Lo mismo ha pasado con otros compuestos de agua: aguamiel, aǵamanil, aguapié, etc. (véase infra). Fuera de los compuestos de agua, ha pasado al m. mandoble (de mano doble), quizá por influencia de golpe. Y con acomodación morfológica nochebueno, nombre de una torta y de un tronco de leña (Dicc. Acad.), quizá por influencia de tronco o pastel. Y tenemos además las vacilaciones dialectales de vinagre:

vinagre, de vino acre (quizá tomado del fr. vinaigre, ant. fr. vinagre), es $\mathrm{m}$. en la lengua general; en Covarrubias el vinagre, pero ya Máteo Alemán, Ortografía castellana, año 1609 , dice que ha oído a las damas "denme la vinagre" (ed. El Colegio de México, 1950, pág. 34); también Jiménez Patón, Instituciones de la gramática española, Baeza, 1614, señalaba la vacilación: "El vinagre se dice en esta tierra, y en Castilla la vinagre" (cit. por Cuervo, § 225); en una canción leonesa-asturiana: "Ya se muriú el burru / que acarriaba la vinagre ..."; se dice la vinagre en el leonés de Maragatería y Astorga (Alonso Garrote, El dialecto vulgar leonés, pág. 78), en Santander (García Lomas, Estudio del dialecto popular montañés, pág. 23), en Cespedosa de Tormes (SÁnchez Sevilla, RFE, XV, 1928, pág. 159), en la región norte de la provincia de Burgos, en gallego (GARCía DE Diego, Gram. gallega, pág. 91) y en la Mancha: "esto tiene mucha vinagre" (informe oral).

Varios nombres de peces, de uso regional, han pasado al m.: 
el cascadura, un pez con largas barbillas bucales (Callychthis callychthis L.), en la Argentina (Malaret, Suplemento; Santamaría lo da como f.: "Nombre vulgar que en la región de Trinidad, en Venezuela, se da al pececillo llamado también curito"); en Cuba el pinta roja, el cabeza de batea, especies de tiburón (ENRIQUe SERPA, Contrabando, novela, La Habana, 1938), pero el Dicc. Acad. registra la pintarroja 'la lija'; y con acomodación morfolóigca, el bocachico, nombre de un pez en Antioquia, Colombia (Flórez, BICC, VII, 1951, pág. 35), caso análogo a el floramarillo, nombre de un arbusto en Venezuela (cf. el quebracho, un árbol de la Argentina, de quiebrahacha).

En resumen, las formas que llevan el adjetivo pospuesto están aún más sujetas al cambio de género, porque el adjetivo altera la terminación y hace entrar al sustantivo en el juego de las fuerzas analógicas. El compuesto que lleva el adjetivo antepuesto es más reacio al cambio, porque el sustantivo conserva mejor su fisonomía y su terminación.

\section{iII. Compuestos de dos sustantivos}

a) Los dos sustantivos tienen el mismo género.-En este caso, el compuesto tiene el género de los sustantivos: la madreperla, la cornamusa, la bocamanga, la zarzamora, la maniobra, el ajoqueso, el gallipavo, el ferrocarril, el mergánsar, la cerapez, la cañamiel, la bocácalle, el oropel (< a u ripelli um), el oropimente (< a u rum + p i g m e n t u m), el ajiaceite, el pezpalo o pejepalo, el pejerrey, el carricoche, el gallipuente, el pasitrote, etc. Sin embargo, hay un caso de cambio de género:

aguamanos, que todavía era f. en el Quijote (II, xxxI, "halló a las doncellas ... con aderezo de darle aguamanos, la cual le dieron con muchas reverencias") y en el Dicc. de Sobrino, de 1705 (Gil Gaya, Tesoro lexic.), figura como m. en el Dicc. Aut. (lo documenta en Narbona, Historia de don Pedro Tenorio) y luego en todas las ediciones del Dicc. Acad.; sin duda ha influído aguamanil y en general la $a$ - (cf. más arriba aguardiente, etc., y más abajo aguapié, etc.).

$\mathrm{Y}$ hay además dos casos dialectales, también compuestos de agua:

aguamiel, que es f. en la lengua general (véase el Dicc. hist. y GiLI Gaya, Tesoro lexic.), es m. en México, donde designa el jugo del maguey: "Un aguamiel muy bueno" (García ICAzbalceta, Vocab. de mexicanismos, lo daba como f.), y en Venezuela, donde es el nombre de una bebida que se prepara con agua y panela: "Este aguamiel está sabroso". Cf. además el hidromel o hidromiel y el acetomiel"1, también el rodomiel 'la miel rosada' (en latín $\mathrm{rhodom} \mathrm{e} \mathrm{l,} \mathrm{n.).} \mathrm{Y}$

${ }^{11}$ Cf. "Vacilaciones de género en los monosílabos", art. cit., pág. 196. 
es también m. en los Andes venezolanos aguasal 'salmuera' (se usa mucho como remedio en los golpes): "El desayuno era una arepa y un aguasal pelao", "Eso es puro aguasal".

Más extraño que el m. de aguamanos o el de aguamiel, que forman sistema con los otros compuestos de agua, es el m. de coliflor (de la col y la flor), frecuente en el habla popular y familiar de la Argentina y de Venezuela, y que seguramente se encuentra también en otras partes ${ }^{12}$; es indudable que se ha perdido la conciencia etimológica, y quizá la terminación -or se siente como m. frente a -ora.

Un caso distinto es el de viacrucis. La lengua general dice el viacrucis, sin duda porque ha sustantivado la locución latina, lo cual se hace regularmente en masculino (véase infra). Pero en gran parte de América hay tendencia a hacerlo f., quizá por el género de via:

las viacrucis en Bogotá, que Cuervo, A puntaciones, $§ 243$, explica por influencia de las estaciones; esta via crucis escriben los autores chilenos Feliu Cruz y Monge Atfaro, Las encomiendas según tasas y ordenanzas, Buenos Aires, 1941, pág. 191; la via crucis, en una tesis doctoral de Buenos Aires; el venezolano Rivodó, Tratado de los compuestos, op. cit., pág. 29, dice que como frase es f. (la via crucis), pero como compuesto es ambiguo (el viacrucis o la viacrucis); don Pedro Henríquez Ureña nos decía que él mismo vacilaba en el uso.

Quizá sean análogas a las de viacrucis las vacilaciones de tranvia, en que, a pesar del origen extranjero (ingl. tramway), se siente la palabra via:

penetró como f. en el Dicc. Acad. ( $11^{\text {a }}$ ed., 1869), pero el uso general prefería el tranvia, sin duda por el francés (le tramway, le tram); la Academia puso el punto en discusión, y el académico Alejandro Oliván (MAE, IV, 1873, págs. 290-306) defendió apasionadamente el f. frente a los traductores y gentes que habían extendido el $\mathrm{m}$. "sin reflexión" (se basaba en que via era f.); sin embargo, la Academia adoptó el m. en la $12^{\text {a }}$ ed. del Dicc. Acad. (1884); en Nuevo México y Guatemala la tranvia.

Dejando de lado las vacilaciones de viacrucis y tranvia, que tienen carácter especial, vemos de nuevo que en los casos de vacilación o cambio (aguamanos, aguamiel, coliflor) se manifiesta regularmente la atracción del masculino ${ }^{13}$.

12 Tiscornia, BDH, III, pág. 94; Garzón, Dicc. argentino, s. v. Tanto en la Argentina como en Venezuela lo hemos oído personalmente con bastante frecuencia. En México (por lo menos en Jalisco) se oye el col, y con menor frecuencia el coliflor. (Tengo este dato, y algunos otros relativos a México y al español clásico, gracias a informaciones de Antonio Alatorre).

${ }^{13}$ Hay sin duda otros casos de uso regional: en México aguabola, m., nombre de un árbol (SANTamaría), atraído por lo tanto por el género común de los árboles, pero no nos consta el origen del nombre. 
b) Los dos sustantivos tienen distinto género.-El género del compuesto está condicionado por la terminación, es decir, por el segundo de los componentes: el cabrahigo (lat. c a p r if i c u s era f.), el calzacalzón, el varapalo, el calicanto, el zapapico, el baciyelmo, el trampantojo, el capisayo, el capricornio (lat. C a p r i cor n u s, m.), el terremoto (lat. t e r a e mot u s, m.), la pezuña (<lat. pedis u n u la), la cornucopia (lat. corn u copia, f.), el arquibanco $\left(\right.$ arca + banco), etc. En el caso de avestruz $(<\mathrm{av} \text { is } \mathrm{t} \mathrm{ruth} \text { i o })^{14}$ o de salitre (<s a $1 \mathrm{n}$ i t $\mathrm{r} \mathrm{u} \mathrm{m}$ ), el género está determinado sin duda por la -o etimológica. Pero si la terminación no es decisiva, ¿cuál será el género? Según MeYer-LüвкE, Gramm., II, $§ 384$, la idea principal es la que determina en estos casos el género: fr. le chef d'cuvre, it. il cannamele. Quizá sea ése el caso en el pejemuller (=el pez mujer), m. como la mayoría de los nombres de peces; en el venezolano el paltó-levita, en que predomina la idea de paltó; o en la fajacinto ("apretándose la fajacinto", en Supercheria de Clarín). Pero en vacabuey, nombre de un árbol silvestre de Cuba, ¿cuál es la idea principal? El m. en este caso está determinado por la significación: es el género regular de los árboles y arbustos ${ }^{15}$. Cuando no es decisiva la significación, nos parece que el género está de nuevo determinado por el segundo sustantivo. Tenemos ante todo los compuestos de agua:

el aguamanil (<lat. a qu a e ma nile, n.) es en realidad prolongación del neutro latino;

el aguamar (de agua + mar);

el aguapié (de agua + pie), que era f. en el Dicc. Aut., en la Gramática de Bello $(\$ 187)$ y en el Dicc. Acad. hasta la $11^{\text {a }}$ ed. (1869), es $\mathrm{m}$. actualmente (el Dicc. Acad. registra el m. desde la $12^{\text {a }}$ ed., 1884); ya Percival, en su Dictionary de 1599 , registraba el m., pero no sabemos si no le engañaba el artículo (un aguapié en el P. Guevara, el aguapié en diversos autores de la época clásica no son conclúyentes sobre el género, pues entonces era general el Armada, el Andalucia, etc., con $e l$ ante $a$ - inacentuada $)^{16}$.

Es evidente que en esos casos el $\mathrm{m}$. se ha impuesto por el uso del artículo $e l$ ante $a$ - (cf. más arriba aguardiente y otros compuestos de

1* Sobre las vacilaciones de avestruz véase EMP, III, pág. 196, y el Dicc. hist., s. v.

${ }_{15}$ Así, la palmacristi, f. por la palma, se ha hecho en el habla popular de Cuba el palmacristi o el palmacriste (Rodríguez Herrera, Género de los nombres, I, pág. 58). En cambio, en Chile la matabuey, nombre de un insecto (ibid.).

${ }^{16}$ Otro compuesto de pie, el ciempiés o cientopiés, se ha hecho en judeoespañol la sintapiés (Subax, "Zum Judenspanischen", en $Z R P h, \mathrm{XXX}$, 1906, pág. 131), quizá por influencia de sinta 'cinta'; en el judeoespañol de Marruecos, el santopiés (BENOLIEL, BAE, XIII, 1926, pág. 520). 
agua). Fuera de esos compuestos tenemos: el puntapié (de la punta + el pie), el bocacaz (de la boca + el caz), el espinapez (en rigor es traducción del it. spina pesce). El capicúa (del cat. capicúa m., de cap 'cabeza' + cúa 'cola') no se siente como compuesto, y el m. se debe sin duda a número.

Observamos de nuevo que en todos esos casos ha prevalecido el masculino.

\section{Compuestos de verbo y sustantivo}

Este tipo de compuestos ${ }^{17}$ tiene gran interés en el estudio del género. Los primeros ejemplos románicos se han documentado desde el siglo virr (en España el primero conocido es Batepalmas, Aragón, 1092), y se aplicaban siempre a personas: eran motes o sobrenombres, una manera burlesca de llamar a alguien (Matamoros, Matasanos, Lameplatos, etc.), y a veces también una alusión al oficio (Batihoja, etc.). Eran todos m., por referirse al hombre (se hacían circunstancialmente f. al aplicarse a la mujer). Luego se extendió el

${ }_{17}$ No vamos a entrar aquí en el origen de estos compuestos. Casi todos los romanistas sostienen que se trata originalmente de una formación de imperativo. El último estudio dedicado a ellos se debe a Leo Spitzer, "Sur quelques emplois métaphoriques de l'impératif", Ro, LXXIII, 1952, págs. 42-61, que plantea la cuestión a fondo. Menḱndez Pidal, Gram. hist., $\S 88_{1}$, sólo ve el imperativo en algunas de las formaciones, y dice: "En general, debe reconocerse en estos verbos el indicativo, que es indudable cuando el compuesto equivale a una oración de relativo o a un participio de presente: destripaterrones 'el que destripa terrones"'. Parece indudable que la formación románica original se ha hecho sobre el imperativo; luego, al extenderse el tipo formativo se ha perdido el sentimiento etimológico. Hoy se siente la forma verbal como tercera persona del presente de indicativo, y en ese sentimiento se basan las nuevas formaciones españolas. Hay que observar que en castellano la inmensa mayoría están formados sobre verbos de la lạ conjugación (forma verbal en -a), pero hay también algunos de la 2 a y $3^{a}$ : rompeolas, rompecabezas (hay diez compuestos de romper), lameplatos, metemuertos, abrepuño, abrojo, batihoja (el Dicc. Acad. trae seis compuestos de batir), cubrecorsé (también seis compuestos de cubrir), torcecuello, etc.

Hemos reunido los siguientes casos en que aparece categóricamente la forma del imperativo: tentemozo (como equivalente del dominguillo se llama también tentetieso en algunas partes de España), tentempié, tentenelaire, ponteduro (cierta golosina mexicana, hecha de maíz; cf. la descripción de MalaRET), hazmerreir. Es indudable también en andaniño, especie de andador. También de imperativo, aunque de tipo distinto, son: correverás, nombre de un juguete infantil, vaivén (presente + imperativo), correveidile. Salsipuedes es frecuente en la toponimia de casi todos los países de América, y designa poblaciones, serranías, canales, arroyos, islas, etc. (en la provincia de Córdoba, Argentina, es nombre de una población, aunque en la región es general el voseo, que impondría otras formàs verbales; cerca de Caracas, en el Ávila, hacia los Venados, es nombre de una subida difícil; en Santo Domingo salsipuedes = "callejón torcido': Henríquez Ureña, BDH, V, pág. 197). En Venezuela, México y Santo Domingo es frecuente el tenteallá, que se emplea para alejar a los niños: 
tipo a la denominación de animales, utensilios o nombres de cosas, y se mantuvo regularmente el m., cualquiera que fuese el sustantivo y la terminación: sacacorchos, saltamontes, pasamano, girasol o mirasol, cortaplumas, cubrecama, portamonedas, portalámparas, matamoscas, paraguas, etc. Este tipo de formación tiene extensión ilimitada en la lengua general y en todos los dialectos, y hay varios centenares de expresiones vivas.

En general, todas ellas se mantienen firmemente en $\mathrm{m}$. Pero al debilitarse o perderse el sentimiento de la composición, es decir, cuando la partícula verbal se fusiona con el sustantivo de tal modo que no se la reconoce inmediatamente como forma verbal (el acento se desplaza al sustantivo), entran en acción los factores analógicos: acomodación del género a la - $a$ final, asociaciones léxicas, etc. Hemos reunido muchos casos de paso al f., pero la cantidad, como veremos, es más aparente que real. Los ordenamos alfabéticamente:

aguzanieve(s), nombre de un pájaro (el Dicc. hist. lo documenta desde Nebrija), ya era f. en el Dicc. de Sobrino, de 1705 (Gill GaYa, Tesoro) y en el Dicc. Aut.; quizá haya influído el nombre de aguanieves, f., que también se le da (se llama además motacilla, andarrios,

"Dile a tu mamá que me mande un poco de tenteallä" (en Santo Domingo, "un poco de tente, o de tenteallá": H. Pieter, BADL, II, 1940, núm. 3, pág. 78; en México, "dile a Refugio que te dé tantito detente"; en los Andes de Venezuela, "la cajita de téngameallä"). JuAn Montalvo usa el haztealla ("la mansedumbre o la ira, la afabilidad o el hazteallá con que aleja de sí a los demás", Siete tratados, Besanzón, 1882, vol. II, pág. 45); SAlvador DE MAdA. RIAGA, el haz-lo-que-quieras ("un amplio e indisciplinado haz-lo-que-quieras", en su Bolivar, México, 1951, vol. I, pág. 146). En Santo Domingo salpafuera 'riña' (Henríquez Ureña, loc. cit.). En Venezuela hemos oído el compónte: "esto no tiene compónte" (también "este libro no tiene pierde", "no tiene pérdida'; en México: "Siga usted derecho y luego tuerce a la izquierda; no tiene pierde"; se dice igualmente no tiene jierre, y humorísticamente reuto sin jierre). En el judeoespañol de Marruecos el correvaite 'la escoba', del mismo tipo que el vaivén 'el rollo de madera para extender la masa' (BENoliel, BAE, XIII, 1926, págs. 519-520). También formas del castellano familiar como un viva la Virgen o un viva la Pepa 'un despreocupado, un frívolo, un fresco'. Y desde luego, latinismos como factótum y vademécum, muy usados. Y además las nomeolvides, y quizá también la siempreviva. Hay un juego de niños llamado el salta tú y dámela tú (ya en Correas s. v. salta: "Salta tú y dámela acá tú"). Julio Casares, en Nuevas normas de prosodia y ortografia de la Real Acad. Española, Madrid, 1952, pág. 47, dice que entre los juegos infantiles tradicionales abundan los compuestos como arráncate rabo, ande la rueda, salga la parida, etc. También son formaciones de imperativo el zampalopresto de González del Castillo o el dejameentrar de Calderón, que menciona (págs. 47, 114-115) entre los compuestos ocasionales, casi siempre festivos, del mismo tipo que siguemepollo.

El paso de designaciones personales a nombres de cosa sigue vivo en una serie de casos: quitamanchas, portacartas, guardarropa, botafuego, tentenel. aire, etc. 
nevatilla, pajarita de las nieves, pizpita, motolita, sanantona, etc.) ; andaboba, nombre antiguo del parar, juego de naipes (el anda. $b o b a$, en Cervantes, con el por la $a$-: véase el Dicc. hist.), probablemente por influencia de boba; andarraya, también nombre de un juego;

atapierna, ligagamba y ligapierna, los tres anticuados, sustituídos por liga, f. (atapierna era al parecer forma rústica y ligagamba ia forma cortesana: véase el Dicc. hist.; Sobrino, en 1705, registraba atapiernas, f.; aquestas ligagambas en Lope de Rueda; las ligas en Tirso y L. F. de Moratín); en cambio, atafarra y atahorma no son compuestos de forma verbal, a pesar de la apariencia;

azotalengua(s) 'amor de hortelano' (planta) en Andalucía;

baticola, nombre de una correa;

botavara, palo de un barco de vela;

calacuerda, toque militar antiguo;

calzatrepas 'trampa, cepo'. voz anticuada; quizá traducción del

fr. la chausse-trape;

cantarrana, juguete infantil de Álava (Dicc. Acad.; Baráibar,

Vocab. de palabras usadas en Alava, s. v.); Cantarrana(s) es muy fre-

cuente en la toponimia hispanoamericana;

cortapluma(s) se usa bastante como f. en la Argentina, porque se ha perdido enteramente el sentimiento etimológico; MonNer SAns, Notas al castellano en la Argentina, s. v., registraba la cortaplumas, "solecismo grosero de muchos jóvenes, algunos profesores y no pocas gentes"; también f. en Chile (Echeverría y Reyes, Voces usadas en Chile, pág. 66); pero el cortaplumas sigue siendo lo más general;

cubrenuca, parte antigua del casco, sin duda por influencia de la nuca; el Dicc. enciclopédico hispanoamericano registra además la cubrejunta, listón de madera;

chotacabras, nombre de ave (el verbo chotar es arcaico); el Dicc. enciclop. hispanoamericano describe las chotacabras, pero entre las variedades menciona el chotacabras europeo;

excusabaraja, una cesta de mimbre; el Dicc. Acad. dice que procede del it. ascosa 'tapada' y barella 'cesta'; no tiene, pues, nada que ver con el verbo excusar;

guardapuerta (documentado ya en el P. Nieremberg), quizá por la antepuerta; guardapierna "chapa de hierro que algunos jinetes ponen en la bota de montar para evitar el roce' en Andalucía (ALcalá Venceslada, Vocab. andaluz, Andújar, 1933, s. v.: "La guardapierna le rompió el pantalón”); guardamalleta, guardasilla y ant. guardarraya (se conserva en Cuba, como vereda, camino o calle entre sembrados), quizá porque se han sentido como compuestos de la guarda (en cambio, guardacalada se explica por buharda calada); guardarropa figura en el Dicc. Acad. como f. en la acepción de 'oficina destinada en palacio y en otras casas y establecimientos públicos para poner en custodia la ropa', pero m. en todas las otras acepciones; quizás, en ese uso especial, por influencia de la guardarropia; cf. it. guardaroba, f.; en La lozana andaluza, LVIII, "descuelga de 
la guardarropa dos quesos mallorquinos y dos parmesanos" (ibid., LXI, "en la guardarropa"); el Dicc. enciclop. hispañoamericano documenta un magnifico guardarropa en Antonio Flores, y el guardarropa 'armario' en Isla y Hartzenbusch;

hurtagua, una especie de regadera;

ligamaza, viscosidad que envuelve las semillas; se ha perdido enteramente el sentimiento etimológico, y es posible que liga se sienta como sustantivo; sobre ligagamba y ligapierna véase más arriba, atapierna;

matabuey 'amarguera', matagallina 'torvisco' en Logroño, matapulgas 'mastranzo' (en San Luis, Argentina, el matapulgas, según la Sra. de Battini), porque se han sentido probablemente como compuestos del sustantivo mata, como en mata rubia; matarrata, un juego de naipes, porque se llama también la mata ("En el juego de la matarrata -dice el Dicc. Aut.- se llaman matas los sietes de espadas y oros. Y aun el mismo juego se suele llamar la mata por abreviar la voz");

mondarrajas, quizá por influencia de mondaduras, que es su equivalente;

paragua, sin $-s$, se usa a veces como f. en la provincia argentina de San Luis (informe de la Sra. de Battini);

pasacólica es f. como cólica, ambos de la terminología médica;

picagallina, nombre de una planta (=álsine); picagrega, nombre de un pájaro (=pega reborda o alcandón);

portabandera, portacaja, portacarabina, las tres del lenguaje militar y asociadas entre sí (la primera es una especie de bandolera, la segunda una correa y la tercera una bolsa pequeña); además portaleña 'portañola', pero es un derivado de portal y no compuesto de portar; portaalmizcle lo daba Bello, Gram., $\$ 187$, como ambiguo, pero la Academia lo conserva como m.; portapaz, utensilio del culto, lo da la Academia como ambiguo (ya lo era para Bello, loc. cit.); en Chile la portamonedas (Echeverría y REYES, pág. 66), que se oye también en Venezuela;

posaverga, voz del antiguo lenguaje náutico;

quitameriendas, nombre de varias especies de plantas; quitacamisa (=arrancacamisa, m), un juego de naipes de Cuba (Malaret; pero Suárez, Dicc. de voces cubanas, y Santamaría lo dan como m.); restañasangre 'ágata de color de sangre' (=alaqueca o cornalina), quizá por ser una piedra (cf. amatista, esmeralda, ant. tupaça, piedra zafira, etc.);

rompecaldera en Logroño (=arce); el f. es doblemente extraño por ser un árbol;

sacabala, instrumento de cirujía (quizá para diferenciar de el sacabalas, instrumento de armeros y artilleros); sacafilásticas (quizá por aguja sacafilásticas); la sacapunta dicen los muchachos de Buenos Aires;

saltarregla; salta(e)mbarca, quizá porque se sobreentendía ropilla (una saltambarca en Vicente Espinel); 
tapafunda, quizá por sentirse el sust. tapa; pero es general el tapaboca(s);

tientaaguja, en que puede haber influído la tienta, como también se llama;

tornaboda, tornaguia, tornapunta, quizá por influencia de la torna (o las tornas), postverbal de tornar;

tragaluz ha sido f. en el Dicc. Acad. hasta la $10^{\text {a }}$ ed., pero hoy figura como m.; en Quintana "un tragaluz, cerrado con unas rejas bien fuertes" (cit. por Cuervo, Nota 38); en la Argentina la tragaluz; el f. se debe sin duda a influencia del género de luz (cf. más arriba trasluz, contraluz).

Claro que no hemos agotado todas las formas, pero en resumen se puede decir que, dentro del conjunto de formaciones de este tipo, que alcanza a varios centenares de voces usadísimas, los casos de paso al f. son realmente pocos. Aunque hemos reunido una lista larga, basta observarla detenidamente para ver que unas son voces antiguas, otras dialectales, de extensión limitada, y otras de tipo técnico, es decir, de uso restringido a ciertas esferas (llama la atención, entre ellas, la cantidad de nombres regionales de plantas: ahogaviejas, azotalenguas, matabuey, matagallina, matapulgas, picagallina, quitameriendas, etc.). Salvo algún caso como tornaboda, que hoy ya no es voz hispánica general (se está perdiendo enteramente la celebración de la tornaboda), por lo común las formas de este tipo se mantienen regularmente en el $\mathrm{m}$. en la lengua culta y general ${ }^{18}$. Las vacilaciones en escala sincrónica, tomando una comunidad hispanohablante cualquiera, son realmente raras.

\section{OTROS COMPUESTOS}

Los adverbios, exclamaciones, conjunciones, pronombres, formas verbales y locuciones latinas se sustantivan en masculino:

un penseque, el pésame o el pláceme, el parabién, los pormenores, el tirese, los quehaceres, el porvenir, el bienestar o el malestar, los tejemanejes, el vademécum, el tedéum, el paternoster, el vaivén, un daca ("los eternos dacas" en Quevedo; andar al daca y toma), el coranvobis, el quita(i)pón, el pasapasa, un sálvese quien pueda ("el sálvese quien pueda de las ideas" en Supercheria, de Clarín), el sánalotodo, el sepancuantos, el correverás, el tira y afloja ("Déjese de tanto tira y afloja"), el bienteveo, un si-es-no-es, un iporvida!. un otrosí, el abecé (en contraste con la a, la $b$, la $c$, como todas las

18 También en francés y en italiano han pasado algunos casos al f. (véase Louis-Francis Meunier, Les composés qui contiennent un verbe à un mode personnel en latin, en français, en italien et en espagnol, Paris, 1875, págs. 270-271). - El paso al $f$. se da con mayor frecuencia en los sustantivos que carecen de $-s$ o que la han perdido (la $-s$ es por lo común signo característico de este tipo de formaciones). 
letras), el alamirré, el bemol (de be + mol 'suave', quizá tomado del francés), el beabá 'la cartilla' ("nunca pasó del be, $a, b a$ ", en Jovellanos), el pujavante, etc.

Lo mismo en una serie de formaciones dialectales o regionales:

el bienmesabe (un dulce de Venezuela, Cuba y Andalucía), el alzapón en Salamanca, el pintapinta, una planta de Colombia, el piquijuye, un insecto de Venezuela y Puerto Rico, el picahuye en Puebla (México), según Ramos y Duarte (Nebrija, Gram., lib. III, cap. VI, registra muerdehuye entre los compuestos castellanos; en España el mordihui 'el gorgojo'; en Cuba y partes de México, al menos en Tamaulipas, el muerdejuye, nombre de un insecto, según Constantino SuÁrez y Ramos y Duarte); el sub(e)ibaja en la Argentina, Venezuela, México, etc. (el juego de niños que en otras partes se llama balancin); el porsiacaso 'el morral' en Venezuela; etc.

Pero la terminación ha producido algunas vacilaciones o ha atraído algunos compuestos de este tipo al f.:

la alzaprima ("buena alzaprima le dió Satanás", en fray Hortensio Paravicino), quizá porque -prima no se siente como forma verbal; la tiramira ("una tira mira de malos nombres" en el Quijote); la ciaboga (una ciaboga en fray Prudencio de Sandoval); la cortapisa (esta cortapisa en el P. Mariana); la picapica (figuraba como m. en el Dicc. encicl. hispanoamericano); la cantimplora (del fr. chantepleure), en que se ha perdido enteramente el sentimiento etimológico; en Chile la topatopa (Dicc. Acad.), nombre de una planta. Pero el ganapierde o la ganapierde ("esta ganapierde de la fortuna" en G. DE Amezúa, Epistolario de Lope de Vega, vol. II, pág. 321 ; figuraba como m. hasta la $14^{\text {a }}$ ed. del Dicc. Acad.; ambiguo desde 1925) y el duermevela o la duermevela, con diferenciación semántica (m. 'sueño ligero del que está dormitando'; f. 'sueño fatigoso y frecuentemente interrumpido').

Se usan en f. las nomeolvides y las siemprevivas, que presuponen flores (pero en México, Venezuela, etc. los nomeolvides). La sin hueso presupone indudablemente la lengua ("mi atrevida sin hueso", escribe Larra). Un caso especial es la alarma (de ;al arma!):

en la lengua clásica era m. (véase el Dicc. hist.: "con fiero alarma cielo y tierra atruena", en VIRUÉs, Monserrate, BAAEE, vol. XVII, pág. 532a), y así se usó hasta hace poco: el Dicc. Acad., Barcia y casi todos los léxicos lo daban como m. (Selva, Guia del buen decir, pág. 9); Uricoechea, en carta del 2 de julio de 1874 a Rufino José Cuervo, decía: "Lo creo m. en el sing., f. en el pl." (Cartas de Cuervo, pág. 103); todavía en 1900 Echeverría y REYEs, pág. 66, daba el f. como erróneo; actualmente está impuesto el f. (la alarma, las alarmas), en lo que puede haber contribuído, además de la termina- 
ción, el sentirlo como postverbal de alarmar (en cambio, siempre el alerta, de ¡alerta! < it. all'erta).

También es f. solfa (de sol $+f a$; f. ya en Quevedo, en contraste con los nombres de las notas musicales) y avemaria (las avemarias, $\mathrm{f}$. ya en Cervantes), sin duda por la -a. El Dicc. Acad. registra como anticuado cumquibus f. 'el dinero'.

En conjunto, la fuerza analógica o la asociación léxica han atraído o tienden a atraer a algunos de esos compuestos al f. Las nuevas formaciones se hacen siempre en masculino.

\section{Vi. Conclusiones}

En el estudio de los compuestos puede confirmarse un hecho que hemos observado en el estudio general del género en castellano: la primacía del masculino sobre el femenino, que es por lo común un género derivado. Los compuestos de verbo y sustantivo, que constituyen el caudal fundamental de los compuestos, son regularmente masculinos. De ahí que una cantidad de otros compuestos, que eran etimológicamente femeninos, se hayan sentido atraídos al masculino. En algunos casos ha contribuído, como fuerza auxiliar, el artículo el ante $a-$ : antifaz, altavoz, aguardiente, aguachirle, aguarrás, aguafuerte, aguazul, aguadulce, aguamanos, aguamanil, aguamiel, aguamar, aguapié. En otros casos la atracción se ha debido a la familia léxica: el verdemar, el verdemontaña, el verdevejiga, por ser nombres de colores; el milflores, el multiflor, el sietenrama, el todaespecie, el palmacristi, etc., y con acomodación morfológica el floramarillo (como el quebracho), por ser nombres de árboles, arbustos, bejucos, etc.; el cascadura, el pinta roja, y aun el bocachico, por ser nombres de peces. Y finalmente, en una serie de casos, por influencias léxicas especiales: el mandoble, quizá por golpe; el nochebueno, quizá por tronco o pastel, etc. El caso más espectacular de esa atracción al masculino es el coliflor en el habla popular y familiar de la Argentina y Venezuela y en el habla rural de Jalisco, México (no tenemos noticias de otras regiones), en contraste con la col (pero el col en Jalisco) y la flor. En la lengua general tenemos de este tipo el aguamanos frente al femenino de agua y de manos.

Pero también hay una serie de cambios a favor del femenino. $\mathrm{Al}$ debilitarse el sentimiento etimológico, entran en juego otras fuerzas, sobre todo la atracción analógica de la terminación o del segundo componente: la guardarropa, la cubrenuca, la tornaboda, etc. Las vacilaciones de duermevela y el femenino de alzaprima, tiramira, ciaboga, cortapisa, picapica, se explican del mismo modo. No es necesario que se borre del todo el sentimiento etimológico para que pueda influir la terminación o el segundo elemento. Pero si se desva- 
nece del todo ese sentimiento, la voz queda sometida a los vaivenes de los sustantivos en $-e$ o en consonante: se explican así las vacilaciones dialectales de coliflor o de vinagre.

El estudio del género de los compuestos tiene, pues, ese interés especial de que sirve hasta cierto punto de piedra de toque del sentimiento etimológico. A este respecto interesan también una serie de formas abreviadas: la moto, la foto, el cine o el cinema, el bus no presentan vacilaciones, que sepamos, porque se siente inmediatamente la forma completa (la motocicleta, la fotografia, el cinematógrafo, el autobús); y desde luego no las presentan tampoco el auto, de el automóvil ${ }^{19}$, el metro, de el metropolitano, porque tienen el asidero morfológico de la -o. La desintegración de los compuestos es también proceso formativo de la lengua: la liga 'cinta con que se aseguran las medias o calcetines', la tienta 'barra de hierro para explorar la calidad del terreno en que se va a edificar' y la mata 'juego de la matarrata' proceden de los antiguos compuestos ligapierna o ligagamba, tientaaguja y matarrata, respectivamente, que eran en su origen masculinos; el vade (pl. los vades) procede de vademécum; el cólera, de el cólera-morbo ${ }^{20}$; el sobre, de el sobrescrito; el reuma, de el reumatismo (en lo cual se ha restablecido, por reducción, la forma original $)^{21}$, y algunas más. Hay casos en que se ha perdido

${ }^{10}$ En francés ha habido vacilación entre une automobile y un automobile, y aunque el Conseil d'Etat se pronunció por el m., terminó por prevalecer el f., que es hoy la forma académica; también lo más general es une auto (cf. Nyrop, Gramm. hist. de la langue fransaise, vol. III, $\$ \S 674$ y 678). Igualmente f. en italiano. En castellano se ha impuesto un automóvil (a favor de la a-) y un auto.

${ }_{20}$ De cholera morbus (terminología médica), aplicado en el siglo xix al 'cólera asiático'. También en fr. le choléra, it. il colera. Pero en algunas regiones del español se ha producido la atracción al f., a pesar de la oposición significativa el cólera $\sim$ la cólera: en Santander la cólera 'el cólera' (Múcica, Dialectos castellanos, Berlín, 1892, pág. 7; García Lomas, Estudio del dial. pop. montañés, San Sebastián, 1922, pág. 23); en el judeoespañol de Marruecos, la que no veamos o la coléra (BENOLIEL, loc. cit., pág. 519).

${ }^{21}$ Según el Dicc. Acad., se usa el reuma o la reuma, pero en el sentido de 'reumatismo' prevalece el m.; la reuma en el Dioscórides de Laguna, en la Fisonomia y varios secretos de naturaleza de CoRTÉs, Zaragoza, 1605, en Malón de Chaide y en Moratín; "hoy en Bogotá, siguiendo a los antiguos, decimos la reuma (el corrimiento)", dice Currvo, Apuntaciones, $\$ 224$; en Chile casi todos lo hacen f. (Román, s. v.); en México las reumas o las riumas, siempre "reumatismo'; también en singular: "tiene una riuma en una pierna" (cf. RAMos $\mathbf{Y}$ Duarte, Dicc. de mex.; Revilla, BDH, IV, págs. 197-198); en la mayor parte del interior de Venezuela la reuma o el reuma 'la rinitis vasomotora, el catarro o romadizo' (también se llama tupición), y es menos general el reuma o la reuma 'el reumatismo'; la reuma 'el reumatismo' también en Santo Domingo (Henríquez Ureña, BDH, V, pág. 172) y en Cespedosa de Tormes (Sánchez Sevilla, RFE, XV, 1928, pág. 159); el Dicc. Acad. establecía la distinción (12ạ y $13^{\mathrm{a}}$ eds.) entre el reuma 'el reumatismo' y la reuma 'el corrimiento' (Ramos y DUarte, 
totalmente la conciencia etimológica: sólo algunos técnicos saben que la radio procede de la radiotelefonía (como un radio de un radiotelegrama) y que la dinamo procede de la máquina dinamoeléctrica ${ }^{22}$, y por ello las dos formas entran en el proceso de acomodación del género a la forma ${ }^{23}$. Las fuerzas conservadoras de la edu-

loc. cit.; Román, s. v.), distinción abandonada actualmente, sin duda porque era ficticia (el francés, en cambio, mantiene rhume y rhumatisme con clara diferenciación); en la Argentina sólo se conoce la significación de 'reumatismo' (el reuma, a veces la reuma); r h e u m a era f. en San Isidoro; hoy la terminología médica tiende a usar el reumatismo como forma única, y a considerar reuma como la forma familiar, abreviada (al contrario de lo histórico, pues lat.

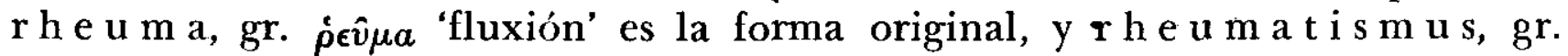

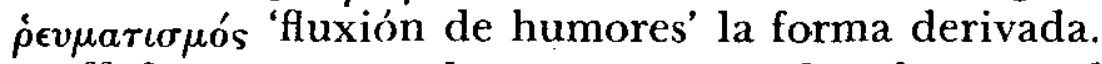

${ }^{22}$ Son tan pocas las personas que lo saben, que la misma Academia ha creído

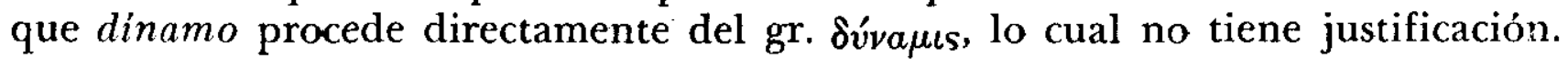

${ }^{23}$ Reunimos a continuación las vacilaciones de radio y dinamo:

la radio es lo general en España y gran parte de América (la Radio Nacional, una radio marca Philips, etc.), como en francés, del que se tomó (hoy se ha generalizado más $l a T$. $S . F$.); la voz es de introducción reciente, y el género vaciló desde el comienzo; el m. se impuso en las Antillas, Venezuela, Ecuador, etc.; en México sólo se conoce el radio; en Venezuela, la lengua culta ha impuesto el $\mathrm{f}$. en el nombre de las estaciones trasmisoras, y así mucha gente cree que es $\mathrm{f}$. la estación y $\mathrm{m}$. el aparato; también se encuentra el m. en el interior de la Argentina, y esporádicamente en la Capital; JuAn RaMón Jiménez, escribiendo en Cuba (RevCu, X, 1937, pág. 36), dice: "El o la radio, como queráis..." (posteriormente hemos encontrado el radio en la prosa de Juan Ramón; así en un artículo reproducido en $A$ riel, San José de Costa Rica, 15 de noviembre de 1941);

la dinamo registra el Dicc. Acad. desde la $13^{\mathrm{a}}$ ed. (1899) en que se incorpora por primera vez (como en fr. la dynamo) ; las dinamos, cuyas dinamos usa RAMón Gómez de la Serna (Don Ramón Maria del Valle Inclán, Buenos Aires-México, 1944, pág. 112; Retratos, pág. 306); la Encicl. Espasa, que usa la dinamo, las dinamos en la descripción electrotécnica, dice en la parte lexicográfica: "Suele por abuso hacerse f. esta voz, considerándola como una especie de máquina" (rechaza igualmente la dinamo, que considera galicismo); en España y América, aun en la literatura técnica, hemos visto el dinamo, con acomodación del género a la -o (en la Argentina es casi el uso exclusivo); en el Perú, Venezuela, México, etc. lo general es el dinamo (Alfonso Reyes dice que no se puede acostumbrar a decir la dinamo, pues desde niño y muchacho oía y decía el dinámo). Y últimamente escribe Julio Casares, BAE, XXXI, 1951, pág. 380: "Es posible que, hablando ex cathedra, haya algún profesor que explique a sus alumnos cómo funciona una dinamo; pero los que construyen y manipulan esa máquina, desde el ingeniero hasta el aprendiz, más los incontables usuarios y servidores de vehículos automóviles, electricistas, etc., todos dicen sin excepción una dinámo".

Se pueden agregar algunos casos más, de uso regional: la micro, en Chile, de el microómnibus, que se ha explicado por influencia de la góndola, como también se llama (es extraño, sin embargo, el f. contra la -o final). En la prensa de Caracas se usa mucho el polio, por la poliomielitis (sin duda es traducción directa del inglés, ya que en los Estados Unidos se ha generalizado the polio). El recurso es frecuentísimo en el argot: el porta 'el portamonedas' (Besses, Dicc. del argot español). Y sobre todo en denominaciones de personas (el buja, el delega, el extra, el limpia, etc.) y en apodos, que salen del marco de este trabajo. 
cación gramatical y de la moderna agitación purista pueden retrasar, y hasta impedir, el cumplimiento del proceso. En materia de género, toda anomalía es posible, como lo prueban la mano y el día.

Universidad Central de Venezuela.

ÁNgel Rosenblat

La antigua malenconia 'melancolia' (se conserva todavía en Santander y Salamanca) se ha transformado en el judeoespañol de Marruecos, por etimologia popular o juego humorístico, en el mal-en-conia (BENoliel, BAE, XII, 1925, pág. $5^{20}$ ), con el género de el mal. 